\title{
Desenvolvimento dos componentes da consciência fonológica no ensino fundamental e correlação com nota escolar
}

\author{
Alessandra Goturo Seabra Capovilla ${ }^{1}$ \\ Natália Martins Dias \\ José Maria Montiel
}

\begin{abstract}
Resumo
Consciência fonológica refere-se à habilidade de refletir sobre a fonologia da linguagem. Sua relação com linguagem escrita é recíproca, ou seja, componentes simples da consciência fonológica auxiliam aquisição de habilidades iniciais de leitura e escrita que facilitam o desenvolvimento de componentes mais complexos e, assim, sucessivamente. Este estudo objetivou avaliar separadamente dez componentes da consciência fonológica em crianças de $1^{\mathrm{a}}$ a $4^{\mathrm{a}}$ série do ensino fundamental, verificando se há aumento com a escolarização e analisando sua correlação com nota escolar. Foi aplicada a Prova de Consciência Fonológica individualmente a 363 crianças. Os escores total e nos dez subtestes da prova aumentaram significativamente ao longo das séries, especialmente da $1^{\text {a }}$ à $3^{\text {a }}$. A nota correlacionou-se com escore total em todas as séries, mas com diferentes subtestes ao longo das séries, havendo maior correlação com subtestes cada vez mais difíceis. Tais resultados corroboram a importância de avaliar separadamente componentes da consciência fonológica.

Palavras-chave: Avaliação psicológica; Metalinguagem; Alfabetização; Fonologia.
\end{abstract}

\section{Development of phonological awareness components in elementary school and relationship to school performance}

\begin{abstract}
Phonological awareness refers to the ability of reflect about the language phonology at the several levels of words, syllables and phonemes. Phonological awareness skills at the most simpler levels foster the development of readingspelling skills at the most elementary levels, which, in turn, foster more advanced reading-spelling skills, and so on, in a virtuous cycle. A sample of 363 first-to fourth-grade elementary school children were individually evaluated by the Phonological Awareness Test. Results showed that total scores as well as individual scores in all the ten phonological awareness skills measured increased with school level, especially from first to third levels. School grades were positively correlated with phonological awareness scores in all school levels, but with different subtests on each level. In latter levels, school grades correlated with the most difficult phonemic subtests. Such results give support to the importance of assessing specific components of phonological awareness.
\end{abstract}

Keywords: Psychological assessment; Meta-language; Literacy; Phonology.

\section{Introdução}

Inúmeras pesquisas, especialmente a partir da década de 1980, têm demonstrado a importância da consciência fonológica para a aquisição da leitura e da escrita (Cardoso-Martins, 1995; Gibson, Hogben \& Fletcher, 2006; Jenkins \& Bowen, 1994; Maluf \& Barrera, 1997; Roazzi \& Dowker, 1989; Simos e cols., 2001; Stanovich, Cunningham \& Cramer, 1984).

A consciência fonológica é uma habilidade complexa que envolve a capacidade de refletir sobre a estrutura fonológica da linguagem oral, incluindo a consciência de que a fala pode ser segmentada e a habilidade de discriminar e manipular tais segmentos (Capovilla \& Capovilla, 2004a, 2004b; Morais, Bertelson, Cary \& Alegria, 1986).

Segundo Supple (1986), a consciência fonológica desenvolve-se gradualmente, à medida que a criança torna-se consciente de palavras, sílabas e fonemas como unidades identificáveis. Dessa forma, a consciência fonológica pode ser dividida em níveis ou componentes, incluindo a consciência suprafonêmica, que se refere à consciência de segmentos maiores que fonemas, tais como sílabas, rimas, aliterações e palavras, e a consciência fonêmica, que se refere especificamente à consciência de fonemas (Morais, 1995).

\footnotetext{
${ }^{1}$ Endereço para correspondência:

Rua Alexandre Rodrigues Barbosa, 45 - 13251-900 - Itatiba-SP

Telefones: (11) 4534-8046 - (11) 9883-9636 - Fax: (11) 4524-1933

E-mail: alessandra.capovilla@saofrancisco.edu.br
}

Universidade São Francisco - Programa de Pós-Graduação Stricto Sensu em Psicologia 
Estudos têm evidenciado que a consciência de segmentos suprafonêmicos desenvolve-se espontaneamente, o que não ocorre com a consciência fonêmica, que parece ser uma habilidade mais complexa (Blischak, 1994; Carroll, Snowling, Stevenson \& Hulme, 2003; Morais e cols., 1986; Thatcher, 2003). Segundo Morais (1995), isso ocorre porque sílabas isoladas e segmentos mais amplos são manifestos como unidades discretas da fala, enquanto os fonemas não o são. Logo, para identificar os fonemas individuais, a criança precisa receber instrução explícita sobre as regras de mapeamento da escrita alfabética.

A consciência fonológica, especialmente no nível fonêmico, é essencial para a aquisição de leitura e escrita em ortografias alfabéticas, ou seja, que mapeiam a fala no nível do fonema, tais como, por exemplo, português, inglês, alemão e espanhol (Goswami, 1997). Isso porque aprender a ler num sistema alfabético pressupõe a capacidade explícita de analisar a estrutura fonêmica da fala (Mann \& Foy, 2003; Torgesen, Wagner \& Rashotte, 1994). A consciência fonológica é especialmente importante para uma dentre as três estratégias possíveis de leitura e escrita, a estratégia alfabética.

Assim, segundo Frith (1985), existem três estratégias para se lidar com a palavra escrita. Na primeira estratégia, denominada logográfica, a leitura e a escrita ainda são incipientes, pois se caracterizam pelo uso de pistas contextuais e não-lingüísticas, tais como as cores, o fundo e a forma global das palavras. $\mathrm{Na}$ segunda estratégia, a alfabética, a criança aprende as regras de correspondências grafofonêmicas. Ou seja, a seqüência grafêmica é segmentada em unidades menores e convertida nos seus respectivos sons e, em seguida, faz-se a junção dos segmentos fonológicos e produz-se a pronúncia da palavra. $\mathrm{O}$ acesso semântico é obtido posteriormente, pelo feedback acústico da forma fonológica produzida em voz alta ou encobertamente. Já a última estratégia, a ortográfica, caracteriza-se pelo processamento visual direto das palavras, ou seja, a criança já possui um léxico mental ortográfico e, a partir dessa representação ortográfica, tem acesso direto ao sistema semântico. Assim, a pronúncia é resgatada como um todo a partir do léxico, sem a mediação fonológica.

Diversos autores têm reconhecido que a estratégia alfabética é essencial para o desenvolvimento da leitura e escrita (para uma revisão, consultar Share, 1995). De fato, a decodificação fonológica possibilita a aquisição das representações ortográficas, permitindo ulterior leitura ortográfica. Além da expansão do léxico ortográfico, a estratégia alfabética também permite a leitura de palavras novas, com as quais mesmo os leitores competentes deparam-se todos os dias.

A consciência fonológica, por sua vez, é essencial para o desenvolvimento da estratégia alfabética, pois possibilita a segmentação da fala no nível do fonema, processo fundamental para que a codificação ocorra. De fato, há vastas evidências da relação entre consciência fonológica e aquisição da linguagem escrita, provenientes tanto de estudos correlacionais, que revelam correlação positiva significativa entre tais habilidades (Bowey, 1994; Morais e cols., 1986), quanto de estudos experimentais, tanto nacionais quanto internacionais, em que intervenções com o desenvolvimento da consciência fonológica promoveram ganhos significativos sobre leitura e escrita (Baker \& Bernhardt, 2004; Capovilla \& Capovilla, 2004a, 2004b; Elbro, Rasmussem \& Spelling, 1996; Torgesen \& Davis, 1996; Santos, 1996; Schneider, Roth \& Ennemoser, 2000; Temple e cols., 2003).

Estudos têm buscado aprofundar a compreensão sobre as relações entre consciência fonológica e linguagem escrita (Foy \& Mann, 2001; Grégoire, 1997; Perfetti, Beck, Bell \& Hughes, 1987). Isso porque, visto que tanto a consciência fonológica quanto a leitura e a escrita são habilidades complexas, diferentes componentes de tais habilidades podem estar mais fortemente relacionados entre si. Assim, a relação entre consciência fonológica e aquisição da linguagem escrita não é unilateral, mas sim recíproca. Segundo Alegria, Leybaert e Mousty (1997), níveis elementares de consciência fonológica propiciam o desenvolvimento de níveis elementares de leitura e escrita que, por sua vez, propiciam o desenvolvimento de níveis mais complexos de consciência fonológica, e assim por diante, em uma interação recíproca. Pesquisas sugerem, por exemplo, que atividades de síntese de fonemas facilitam o desenvolvimento da leitura de pseudopalavras, enquanto esta, por sua vez, facilita a subtração de fonemas (Perfetti e cols., 1987).

Demont (1997) investigou a relação entre seis diferentes componentes da consciência fonológica e leitura em um estudo longitudinal, com crianças francesas. Foram aplicadas provas de contagem, manipulação e transposição de sílabas e de fonemas, bem como provas de leitura em cinco diferentes momentos ao longo de três anos, em que as crianças tinham de seis a oito anos de idade. Os resultados revelaram que a correlação entre leitura e consciência fonológica tendeu a diminuir com o aumento das idades das crianças, e que os subtestes de manipulação foram os que apresentaram correlações mais fortes com leitura.

Dessa forma, há evidências cada vez mais claras sobre a necessidade de não se considerar, equivocadamente, a consciência fonológica como uma habilidade unitária, mas sim analisá-la em seus diferentes componentes, verificando a relação de cada componente com diferentes etapas da aquisição de leitura e escrita. Segundo Muter, Snowling e Taylor (1994), em virtude da complexidade da consciência fonológica, nas tarefas que

Psico-USF, v. 12, n. 1, p. 55-64, jan./jun. 2007 
visam avaliar tal habilidade devem ser incluídas diferentes atividades, tais como manipulação de sílabas e de fonemas, julgamento de rimas e de aliterações. O presente estudo insere-se nesse contexto ao analisar dez diferentes componentes da consciência fonológica em crianças de $1^{\mathrm{a}}$ a $4^{\mathrm{a}}$ série do ensino fundamental, verificando o aumento de desempenho desses componentes com a progressão escolar. Foi analisada, também, a correlação entre tais componentes e as notas escolares em cada série, de forma a verificar se, nas séries iniciais, componentes mais elementares, como os suprafonêmicos, correlacionam-se mais fortemente com as notas e se, nas séries avançadas, a maior correlação ocorre entre notas e componentes mais complexos, como os fonêmicos.

\section{Método}

\section{Participantes}

Participaram deste estudo 394 crianças de ambos os sexos, estudantes de $1^{\mathrm{a}}$ a $4^{\mathrm{a}}$ série do ensino fundamental de uma escola municipal de uma cidade do interior do estado de São Paulo. Participaram todas as crianças daquela escola cujos responsáveis assim autorizaram, não tendo sido usado qualquer critério de exclusão a priori, tal como repetência escolar. As crianças pertenciam a quatro classes de $1^{\text {a }}$ série, seis classes de $2^{\mathrm{a}}$ série, três classes de $3^{\mathrm{a}}$ série e quatro classes de $4^{\mathrm{a}}$ série, e tinham idades variando de 6 anos e 7 meses a 15 anos e 4 meses. Devido a esta grande variabilidade de idade, foram posteriormente excluídos os outliers por idade em cada série. Dessa forma, excluíram-se quatro crianças de $1^{\text {a }}$ série, cinco de $2^{\text {a }}$ série, oito de $3^{\text {a }}$ série e 14 de $4^{a}$ série, restando, ao todo, 363 crianças.

$\mathrm{Na}$ amostra final de 363 participantes, havia 84 crianças de $1^{a}$ série (idade média de 85,43 meses, desvio padrão de 5,27 meses), 128 crianças de 2a (idade média de 103,89 meses, desvio padrão de 10,94 meses), 60 crianças de $3^{\text {a }}$ (idade média de 109,42 meses, desvio padrão de 6,03 meses) e 91 crianças de $4^{\text {a }}$ série (idade média de 123,66 meses, desvio padrão de 6,92 meses).

\section{Instrumentos}

Foi usada a Prova de Consciência Fonológica por Produção Oral - PCFO (Capovilla \& Capovilla, 1998, 2004a), que avalia a habilidade de manipular os sons da fala, expressando oralmente o resultado dessa manipulação. A PCFO avalia dez componentes da consciência fonológica, sendo composta por dez subtestes, cada um com dois itens de treino e quatro de teste. Os subtestes de Síntese Silábica e Síntese Fonêmica avaliam a capacidade da criança de unir sílabas e fonemas, respectivamente, apresentados Psico-USF, v. 12, n. 1, p. 55-64, jan./jun. 2007 oralmente pelo aplicador. O de Julgamento de Rima avalia a capacidade da criança de discriminar rimas, ou seja, dentre três palavras faladas, ela deve dizer quais são as duas que terminam com o mesmo som. O subteste de Julgamento de Aliteração avalia a capacidade da criança de discriminar aliterações, ou seja, dentre três palavras faladas, ela deve dizer quais são as duas que começam com o mesmo som. Os subtestes de Segmentação Silábica e Segmentação Fonêmica verificam a capacidade da criança de separar palavras apresentadas oralmente pelo aplicador em sílabas e de fonemas, respectivamente. Os de Manipulação Silábica e Manipulação Fonêmica avaliam a capacidade de formar novas palavras por meio da adição e da subtração de uma sílaba ou de um fonema, respectivamente. Finalmente, os subtestes de Transposição Silábica e Transposição Fonêmica verificam a capacidade da criança de criar palavras oralmente por meio de inversão silábica ou fonêmica.

O resultado das crianças na PCFO é apresentado como escore ou freqüência de acertos, sendo o máximo possível de 40 acertos. A prova é de aplicação individual com duração aproximada de 20 minutos. Estudos anteriores já evidenciaram a validade e a precisão do instrumento para crianças do ensino infantil e fundamental (Capovilla \& Capovilla, 2004a; Ferracini, 2005), disponibilizando, inclusive, normas para crianças de pré 1 a $2^{\text {a. }}$ série obtidas a partir de resultados de crianças de escola particular (Capovilla \& Capovilla, 1998; 2004a; Capovilla, Capovilla \& Silveira, 1998) e normas para crianças de $1^{\mathrm{a}}$ a $4^{\mathrm{a}}$ série de escolas públicas (Varanda, 2006).

Além da aplicação da PCFO, foram obtidas as notas escolares das crianças. Naquela escola, as notas eram emitidas separadamente para as disciplinas de português, matemática, ciências, geografia e história, todas ministradas por uma mesma professora para cada classe. Tais notas variavam em uma escala de 0 a 10 pontos, tendo sido coletadas para uso no presente estudo. Além dessas, havia notas para educação física, educação artística e informática, que não foram consideradas nesta pesquisa por serem menos relacionadas ao desempenho acadêmico.

\section{Procedimento}

Após assinatura do Termo de Consentimento Livre e Esclarecido, tanto pelos diretores da instituição participante quanto pelos responsáveis pelas crianças, foi iniciada a coleta de dados. A PCFO foi aplicada individualmente às 394 crianças, em sessão única com duração aproximada de 20 minutos por participante. A avaliação ocorreu em sala disponibilizada pela instituição, durante o período escolar regular. 


\section{Resultados}

Foram conduzidas análises descritivas e inferenciais usando o pacote estatístico SPSS - Statistical Package for Social Sciences, versão 13.0. O desempenho médio na PCFO, incluindo os dez subtestes, foi de 25,5 pontos, com desvio padrão de 7,5 pontos, mínimo de 5,5 pontos e máximo de 40 pontos. Os desempenhos na PCFO para cada série escolar distribuíram-se segundo a curva normal, conforme teste de Kolmogorov-Smirnov. A Figura 1 representa os escores médios em cada subteste da PCFO, em ordem crescente de dificuldade. Pode-se observar que os subtestes suprafonêmicos foram mais fáceis que os fonêmicos.

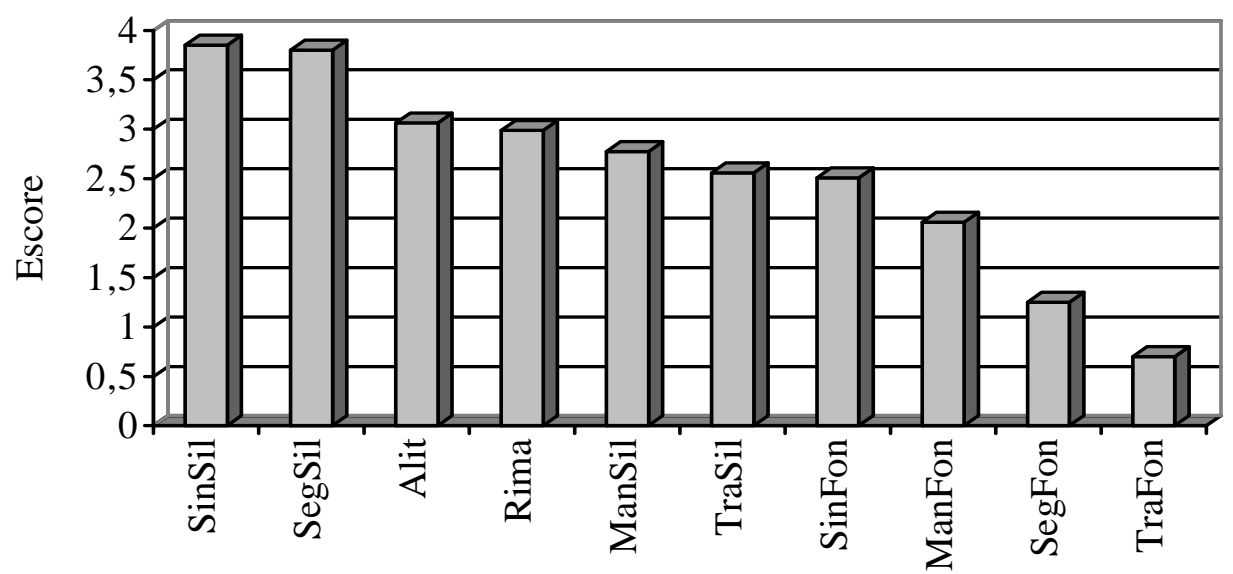

Figura 1 - Escores médios nos dez subtestes da PCFO em ordem crescente de dificuldade para a amostra como um todo

De forma a verificar se os escores aumentaram com a progressão das séries, foi conduzida uma Análise de Covariância tendo como fator a série escolar (com quatro níveis, de $1^{\text {a }}$ a $4^{\text {a }}$ série) e como variáveis dependentes os escores total e em cada subteste da PCFO. Visto que, mesmo após a exclusão dos outliers, o desvio padrão da idade em cada série continuou elevado, a idade em meses foi usada como covariante. Os escores de cada série e seus respectivos erros padrão, corrigidos pela Ancova, encontram-se sumariados na Tabela 1.

Tabela 1 - Escores médios, com erros padrão entre parênteses, na PCFO e em cada subteste para cada série escolar e no geral

\begin{tabular}{cccccc}
\hline & $1^{a}$ série & $2^{\text {a }}$ série & $3^{\text {a }}$ série & $4^{\text {a }}$ série & Média geral \\
\hline PCFO & $16,57(1,06)$ & $24,00(, 56)$ & $29,63(0,82)$ & $33,46(0,99)$ & $25,92(0,34)$ \\
Sin. Sil. & $3,62(0,06)$ & $3,86(0,03)$ & $3,96(0,04)$ & $3,99(0,05)$ & $3,86(0,02)$ \\
Sin. Fon. & $1,68(0,21)$ & $2,44(0,11)$ & $2,99(0,16)$ & $3,06(0,19)$ & $2,54(0,07)$ \\
Rima & $2,07(0,16)$ & $2,83(0,08)$ & $3,37(0,12)$ & $3,81(0,15)$ & $3,02(0,05)$ \\
Aliteração & $2,06(0,18)$ & $2,85(0,09)$ & $3,71(0,14)$ & $3,89(0,17)$ & $3,13(0,06)$ \\
Seg. Sil. & $3,40(0,08)$ & $3,75(0,04)$ & $3,92(0,07)$ & $4,18(0,08)$ & $3,81(0,03)$ \\
Seg. Fon. & $0,45(0,24)$ & $1,14(0,13)$ & $1,29(0,19)$ & $2,11(0,22)$ & $1,25(0,08)$ \\
Man. Sil. & $1,73(0,20)$ & $2,57(0,10)$ & $3,32(0,15)$ & $3,68(0,18)$ & $2,82(0,06)$ \\
Man. Fon. & $0,63(0,20)$ & $1,74(0,11)$ & $2,82(0,16)$ & $3,35(0,19)$ & $2,14(0,07)$ \\
Transp. Sil. & $0,96(0,25)$ & $2,41(0,13)$ & $3,15(0,20)$ & $3,86(0,24)$ & $2,60(0,08)$ \\
Transp. Fon. & $0,02(0,18)$ & $0,40(0,09)$ & $1,09(0,14)$ & $1,52(0,17)$ & $0,75(0,06)$ \\
\hline
\end{tabular}

A Tabela 2 sumaria os resultados da Ancova, incluindo $F, p$ e as diferenças significativas entre séries obtidas no teste post-hoc de comparação de pares de Scheffé. Como pode ser observado, tanto o escore total quanto os escores nos dez subtestes da PCFO aumentaram de forma significativa com a progressão escolar. Quanto a análises de comparação de pares, pode-se observar que, para escore total na PCFO, houve aumento da $1^{\text {a }}$ para a $2^{\text {a }}$ série, e desta para a $3^{\text {a }}$, porém não houve aumento significativo da $3^{\mathrm{a}}$ para a $4^{\mathrm{a}}$ série. Tal padrão também foi observado para os subtestes de Rima, Aliteração, Manipulação Silábica, 
Manipulação Fonêmica e Transposição Fonêmica. Além dos resultados sumariados na Tabela 3, houve efeito significativo da covariante idade sobre os escores na PCFO total e nos subtestes de Síntese Fonêmica,
Aliteração, Segmentação Silábica, Segmentação Fonêmica, Manipulação Fonêmica, Transposição Silábica.

Tabela 2 - Resultados da Ancova tendo série como fator, idade como covariante e desempenhos total e em cada subteste da PCFO como variáveis dependentes, incluindo $F, p$ e diferenças significativas entre séries obtidas no teste post-hoc de comparação de pares de Scheffé

\begin{tabular}{cccc}
\hline & $F$ & $p$ & $\begin{array}{c}\text { Diferenças significativas } \\
\text { entre séries - Scheffé }\end{array}$ \\
\hline PCFO & $F(3,358)=34,15$ & 0,000 & $1<2<3,4$ \\
Sin. Sil. & $F(3,358)=7,47$ & 0,000 & $1<2,3,4$ \\
Sin. Fon. & $F(3,358)=7,16$ & 0,000 & $1<3,4$ \\
Rima & $F(3,358)=15,93$ & 0,000 & $1<2<3,4$ \\
Aliteração & $F(3,358)=17,50$ & 0,000 & $1<2<3,4$ \\
Seg. Sil. & $F(3,358)=9,91$ & 0,001 & $1<4$ \\
Seg. Fon. & $F(3,358)=5,78$ & 0,000 & - \\
Man. Sil. & $F(3,358)=14,41$ & 0,000 & $1<2<3,4$ \\
Man. Fon. & $F(3,358)=25,88$ & 0,000 & $1<2<3,4$ \\
Transp. Sil. & $F(3,358)=16,27$ & 0,000 & $1<2,3,4 ; 2<4$ \\
Transp. Fon. & $F(3,358)=12,65$ & 0,000 & $1<2<3,4$ \\
\hline
\end{tabular}

Visando verificar as inter-relações entre o escore total na PCFO e nos seus dez subtestes, foram conduzidas análises de correlação de Pearson, consideran- do as quatro séries escolares em conjunto. A Tabela 3 sumaria os resultados obtidos. Pode-se observar que todas as correlações foram positivas e significativas.

Tabela 3 - Matriz de correlações entre escore total e nos subtestes da PCFO para as quatro séries conjuntamente

\begin{tabular}{|c|c|c|c|c|c|c|c|c|c|c|c|}
\hline & & PCFO & $\begin{array}{l}\text { Sin. } \\
\text { Sil. }\end{array}$ & $\begin{array}{l}\text { Sin. } \\
\text { Fon. }\end{array}$ & Rima & Alit. & $\begin{array}{l}\text { Seg. } \\
\text { Sil. }\end{array}$ & $\begin{array}{l}\text { Seg. } \\
\text { Fon. }\end{array}$ & $\begin{array}{c}\text { Man. } \\
\text { Sil. }\end{array}$ & $\begin{array}{l}\text { Man. } \\
\text { Fon. }\end{array}$ & $\begin{array}{c}\text { Trans. } \\
\text { Sil. }\end{array}$ \\
\hline \multirow[t]{2}{*}{ Sin. Sil. } & $r$ & $0,443^{* *}$ & & & & & & & & & \\
\hline & $p$ & 0,000 & & & & & & & & & \\
\hline \multirow[t]{2}{*}{ Sin. Fon. } & $r$ & $0,637 * *$ & $0,318^{* *}$ & & & & & & & & \\
\hline & $p$ & 0,000 & 0,000 & & & & & & & & \\
\hline \multirow[t]{2}{*}{ Rima } & $r$ & $0,733^{* *}$ & $0,324 * *$ & $0,369^{* *}$ & & & & & & & \\
\hline & $p$ & 0,000 & 0,000 & 0,000 & & & & & & & \\
\hline \multirow[t]{2}{*}{ Aliteração } & $r$ & $0,743^{* *}$ & $0,314^{* *}$ & $0,388^{* *}$ & $0,599 * *$ & & & & & & \\
\hline & $p$ & 0,000 & 0,000 & 0,000 & 0,000 & & & & & & \\
\hline \multirow[t]{2}{*}{ Seg. Sil. } & $r$ & $0,394 * *$ & $0,244 * *$ & $0,202^{* *}$ & $0,222^{* *}$ & $0,266^{* *}$ & & & & & \\
\hline & $p$ & 0,000 & 0,000 & 0,000 & 0,000 & 0,000 & & & & & \\
\hline \multirow[t]{2}{*}{ Seg. Fon. } & $r$ & $0,642^{* *}$ & $0,233^{* *}$ & $0,417 * *$ & $0,362^{* *}$ & $0,333^{* *}$ & $0,202^{* *}$ & & & & \\
\hline & $p$ & 0,000 & 0,000 & 0,000 & 0,000 & 0,000 & 0,000 & & & & \\
\hline \multirow[t]{2}{*}{ Man. Sil. } & $r$ & $0,766^{* *}$ & $0,315^{* *}$ & $0,352^{* *}$ & $0,613^{* *}$ & $0,558^{* *}$ & $0,247 * *$ & $0,334 * *$ & & & \\
\hline & $p$ & 0,000 & 0,000 & 0,000 & 0,000 & 0,000 & 0,000 & 0,000 & & & \\
\hline \multirow[t]{2}{*}{ Man. Fon. } & $r$ & $0,802^{* *}$ & $0,334 * *$ & $0,469^{* *}$ & $0,517 * *$ & $0,536^{* *}$ & $0,209^{* *}$ & $0,501 * *$ & $0,591 * *$ & & \\
\hline & $p$ & 0,000 & 0,000 & 0,000 & 0,000 & 0,000 & 0,000 & 0,000 & 0,000 & & \\
\hline \multirow[t]{2}{*}{ Trans. Sil. } & $r$ & $0,656^{* *}$ & $0,196^{* *}$ & $0,246^{* *}$ & $0,399 * *$ & $0,467^{* *}$ & 0,290 ** & $0,286^{* *}$ & $0,503^{* *}$ & $0,416^{* *}$ & \\
\hline & $p$ & 0,000 & 0,000 & 0,000 & 0,000 & 0,000 & 0,000 & 0,000 & 0,000 & 0,000 & \\
\hline \multirow[t]{2}{*}{ Trans. Fon. } & $r$ & $0,514 * *$ & $0,176^{* *}$ & $0,289 * *$ & $0,319^{* *}$ & $0,282^{* *}$ & $0,151^{* *}$ & $0,251 * *$ & $0,305^{* *}$ & $0,393 * *$ & $0,142^{* *}$ \\
\hline & $p$ & 0,000 & 0,001 & 0,000 & 0,000 & 0,000 & 0,004 & 0,000 & 0,000 & 0,000 & 0,007 \\
\hline
\end{tabular}

** $p<0,01$ 
Com o objetivo de verificar a relação de cada componente da consciência fonológica com as notas escolares em cada série escolar, foram conduzidas análises de correlação de Pearson. Conforme descrito no método, foram coletadas as notas para as disciplinas de português, matemática, ciências, geografia e história. As notas eram emitidas por uma única professora por classe e variavam em uma escala de 0 a 10 pontos. Inicialmente foi verificada a correlação entre as notas nas cinco disciplinas. Todas as correlações foram significativas, com coeficientes de correlação muito altos e $p<0,000$, sendo o maior coeficiente de correlação entre as disciplinas de geografia e história $(r=0,986)$ e o menor entre ciências e matemática $(r=0,941)$. Devido a esta forte correlação entre as notas nas cinco disciplinas, foi calculada a nota média para ser usada nas análises de correlação com os escores em consciência fonológica.

A Tabela 4 sumaria as correlações, separadamente para cada uma das quatro séries e no geral, entre a nota escolar e os escores totais e em cada subteste da PCFO. Os subtestes encontram-se ordenados por grau crescente de dificuldade para a amostra como um todo, conforme a Figura 1.

Tabela 4 - Matriz de correlações, separadamente para cada uma das quatro séries e, no geral, entre a nota escolar e os escores total e em cada subteste da PCFO, ordenados por grau crescente de dificuldade

\begin{tabular}{ccccccc}
\hline \multirow{2}{*}{ PCFO } & & Nota & Nota & Nota & Nota & Geral \\
& $r$ & $0,828^{* *}$ & $0,682^{* *}$ & $0,506^{* *}$ & $0,562^{* *}$ & $0,514^{* *}$ \\
& $p$ & 0,000 & 0,000 & 0,000 & 0,000 & 0,000 \\
Sin Sil & $r$ & $0,629^{* *}$ & $0,241^{* *}$ & $0,281^{*}$ & 0,033 & $0,261^{* *}$ \\
& $p$ & 0,000 & 0,007 & 0,038 & 0,759 & 0,000 \\
Seg Sil & $r$ & $0,573^{* *}$ & 0,121 & 0,129 & $-0,022$ & $0,196^{* *}$ \\
& $p$ & 0,000 & 0,181 & 0,348 & 0,839 & 0,000 \\
Aliteração & $r$ & $0,710^{* *}$ & $0,488^{* *}$ & 0,203 & $0,271^{* *}$ & $0,396^{* *}$ \\
& $p$ & 0,000 & 0,000 & 0,136 & 0,010 & 0,000 \\
Rima & $r$ & $0,624^{* *}$ & $0,376^{* *}$ & $0,393^{* *}$ & 0,167 & $0,308^{* *}$ \\
& $p$ & 0,000 & 0,000 & 0,003 & 0,116 & 0,000 \\
Man Sil & $r$ & $0,587^{* *}$ & $0,525^{* *}$ & $0,470^{* *}$ & $0,338^{* *}$ & $0,398^{* *}$ \\
& $p$ & 0,000 & 0,000 & 0,000 & 0,001 & 0,000 \\
Trans Sil & $r$ & $0,664^{* *}$ & $0,431^{* *}$ & 0,154 & $0,460^{* *}$ & $0,399^{* *}$ \\
& $p$ & 0,000 & 0,000 & 0,263 & 0,000 & 0,000 \\
Sin Fon & $r$ & $0,606^{* *}$ & $0,386^{* *}$ & 0,174 & $0,277 * *$ & $0,337^{* *}$ \\
& $p$ & 0,000 & 0,000 & 0,203 & 0,008 & 0,000 \\
Man Fon & $r$ & $0,609^{* *}$ & $0,516^{* *}$ & 0,252 & $0,345^{* *}$ & $0,322^{* *}$ \\
& $p$ & 0,000 & 0,000 & 0,064 & 0,001 & 0,000 \\
Seg Fon & $r$ & $0,530^{* *}$ & $0,503^{* *}$ & $0,270^{*}$ & $0,425^{* *}$ & $0,434^{* *}$ \\
& $p$ & 0,000 & 0,000 & 0,046 & 0,000 & 0,000 \\
Trans Fon & $r$ & $0,258^{*}$ & 0,125 & $0,266^{*}$ & $0,369^{* *}$ & $0,163^{* *}$ \\
& $p$ & 0,026 & 0,166 & 0,050 & 0,000 & 0,002 \\
\hline
\end{tabular}

$* * p<0,01$

Pode-se observar, a partir da Tabela 4, que o escore geral na PCFO apresentou correlação significativa com a nota escolar em todas as quatro séries conjuntamente $(r=0,514)$, bem como com as notas em cada série separadamente. Tal correlação foi muito alta na $1^{\text {a }}$ série $(r=0,828)$, diminuindo para alta na $2^{\text {a }}$ série $(\mathrm{r}=0,682)$ e diminuindo ainda mais, para moderada, na $3^{a}(r=0,506)$ e na $4^{a}$ séries $(r=0,562)$.

Portanto, as correlações entre nota escolar e escores em consciência fonológica para cada série revelaram diferentes padrões. Pode-se observar que a maior correlação com a nota tendeu a ser com subtestes mais fáceis nas séries iniciais, progredindo para subtestes mais difíceis nas séries mais avançadas. Assim, na $1^{\text {a }}$ série, a maior correlação foi com Aliteração; na $2^{a}$ e na $3^{a}$ séries, foi com Manipulação Silábica; e, finalmente, na $4^{a}$ série, a maior correlação foi com Transposição Silábica. 


\section{Discussão}

Os resultados desta pesquisa revelaram que os escores na PCFO aumentaram de forma significativa com a progressão escolar, especificamente da $1^{a}$ à $3^{a}$ série do ensino fundamental. Tal fato corrobora estudos prévios, demonstrando que a consciência fonológica desenvolve-se gradualmente, à medida que a criança torna-se consciente de palavras, sílabas e fonemas como unidades identificáveis (Supple, 1986). Assim, o aumento dos escores na PCFO ao longo das séries era, de fato, esperado (Bowey, 1994; Capovilla, Capovilla \& Silveira, 1998; Warrick, Rubin \& Rowe-Walsh, 1993).

Deve-se observar que as análises de comparação de pares não revelaram aumento significativo no escore na PCFO da $3^{a}$ para a $4^{a}$ série. Uma possível explicação para tal fato refere-se à inclusão de crianças repetentes na presente amostra. Visto que a escola participante do estudo adotava o sistema de progressão continuada, a retenção de alunos ocorria principalmente na $4^{a}$ série do ensino fundamental, e não nas séries anteriores. Isso pode ter levado a um achatamento dos escores em consciência fonológica nessa série. Não foi possível refazer as análises excluindo os alunos repetentes visto que a escola disponibilizou apenas o registro das repetências das séries cursadas na própria escola. Ou seja, alunos que haviam sido transferidos de outras escolas não tinham registros referentes ao possível histórico de repetência, o que inviabilizou tal análise. Estudos posteriores deverão investigar mais especificamente se, com a exclusão de alunos repetentes, as diferenças entre os escores na PCFO da $3^{\text {a }}$ para a $4^{\text {a }}$ série tornam-se estatisticamente significativas, como foi observado em outras pesquisas (por exemplo, Varanda, 2006).

Os escores em cada um dos dez subtestes da PCFO também aumentaram de forma significativa com a progressão escolar. Análises de comparação de pares revelaram que, para metade dos subtestes, as diferenças observadas foram semelhantes àquelas observadas para $\mathrm{o}$ escore total, ou seja, aumento da $1^{a}$ para a $2^{a}$ série, e desta para a $3^{a}$, porém não da $3^{a}$ para a $4^{a}$ série. Em outros subtestes tais diferenças não foram encontradas. Por exemplo, no subteste de Segmentação Fonêmica não houve qualquer diferença significativa entre as séries, apesar de os escores terem aumentado de forma linear ao longo das quatro séries. Tal ausência de significância pode ser graças a variabilidade dos escores em cada série. Nesse caso, talvez o aumento no número de participantes diminua essa variabilidade e revele diferenças significativas, o que deve ser investigado em estudos futuros.

Observou-se que, para as quatro séries conjuntamente, os subtestes suprafonêmicos foram mais fáceis que os fonêmicos, com a seguinte ordem crescente

Psico-USF, v. 12, n. 1, p. 55-64, jan./jun. 2007 de dificuldade: Síntese Silábica, Segmentação Silábica, Aliteração, Rima, Manipulação Silábica, Transposição Silábica, Síntese Fonêmica, Manipulação Fonêmica, Segmentação Fonêmica e Transposição Fonêmica. Tal padrão corrobora a bibliografia, evidenciando que a consciência de segmentos suprafonêmicos, como a consciência de silabas, rimas e aliterações, desenvolve-se antes das experiências formais de alfabetização (Share, 1995; Warrick, Rubin \& Rowe-Walsh, 1993). De fato, os escores em Síntese e Segmentação Silábicas situaram-se próximo ao teto, de quatro pontos, logo na $1^{\text {a }}$ série $(3,4 \mathrm{e}$ 3,62 pontos, respectivamente). Por outro lado, os subtestes fonêmicos apresentaram escores bastante baixos na $1^{\text {a }}$ série, sendo o maior deles de 1,68 ponto, em Síntese Fonêmica, e o menor de apenas 0,02 ponto, em Transposição Fonêmica.

Tais resultados estão de acordo com pesquisas internacionais, que sugerem que a consciência fonêmica desenvolve-se posteriormente à suprafonêmica. Apesar deste ter sido um estudo correlacional e, portanto, não permitir a análise da contribuição causal da linguagem escrita para a consciência fonológica e vice-versa, os resultados são condizentes com pesquisas sugerindo que a consciência fonêmica desenvolve-se somente com a exposição a instruções explícitas sobre as regras de mapeamento da escrita alfabética (Bertelson \& De Gelder, 1989; Morais e cols., 1986).

Foram observadas, também, correlações positivas significativas entre o escore total na PCFO e nos seus dez subtestes, como esperado teoricamente (Demont, 1997). As correlações entre o escore total da PCFO e seus subtestes foram de moderadas a altas, sendo a maior correlação entre PCFO e Manipulação Fonêmica, $\operatorname{com} r=$ 0,802. Já as correlações entre os subtestes foram de baixas a moderadas, com coeficientes variando entre 0,613 e 0,142 . Tais coeficientes, alguns bastante baixos, corroboram a necessidade de considerar separadamente diferentes componentes da consciência fonológica. Além disso, os coeficientes tenderam a ser maiores quando os subtestes correlacionados eram ambos suprafonêmicos ou ambos fonêmicos, revelando certa independência entre diferentes níveis de consciência fonológica.

Além de ficar evidente que certos componentes da consciência fonológica apresentam correlação baixa entre si, este estudo demonstrou, também, que a relação entre consciência fonológica e nota escolar muda com a progressão das séries. Portanto, ao analisar as correlações entre escores nos dez subtestes da PCFO e a nota escolar em cada série, este estudo contribuiu para o mapeamento de quais componentes estabelecem correlações mais importantes com o desempenho ao longo das séries.

Assim, o escore total na PCFO apresentou correlação positiva significativa com nota em todas as 
quatro séries escolares, porém tal correlação tendeu a diminuir com o passar das séries, o que também foi observado por Demont (1997). Isso pode sugerir que as habilidades de consciência fonológica apresentam maior importância relativa para a nota no início da alfabetização, haja vista a leitura nas séries iniciais ser mediada basicamente pela estratégia fonológica (Frith, 1985). Por outro lado, na $3^{\mathrm{a}}$ e $4^{\mathrm{a}}$ séries, em que as correlações entre a PCFO e as notas escolares apresentaram-se mais modestas, pode-se inferir que esses estudantes estejam utilizando-se de outra estratégia de leitura, tal como a lexical.

O mesmo tendeu a ocorrer com os escores na maioria dos subtestes, ou seja, de forma geral, as correlações entre os subtestes e a nota tenderam a diminuir com a progressão escolar. Dentre os quatro subtestes mais fáceis, três deixaram de ter correlação significativa com nota na $4^{a}$ série, a saber, Segmentação Silábica, Segmentação Fonêmica e Rima. Por outro lado, o subteste mais difícil da prova, de Transposição Fonêmica, teve sua correlação com nota aumentada da $1^{a}$ para a $4^{a}$ série.

Dessa forma, as correlações entre nota escolar e escores para cada série revelaram diferentes padrões, e a maior correlação com a nota tendeu a ser com subtestes mais fáceis nas séries iniciais, progredindo para subtestes mais difíceis nas séries mais avançadas. Tais resultados sugerem, portanto, que a importância relativa de cada componente da consciência fonológica muda com a progressão da série. Enquanto na 1a série o componente mais fortemente correlacionado com a nota foi a Aliteração, nas séries intermediárias foi a Manipulação Silábica e, na 4a série, foi a Transposição Silábica. Tais resultados apresentam semelhanças com os de Demont (1997), que aplicou provas de consciência fonológica e de leitura a crianças francesas em cinco diferentes momentos, desde os seis até os oito anos de idade. Demont observou que a leitura apresentou correlação significativa principalmente com tarefas de manipulação silábica e fonêmica, mas correlações menores com contagem silábica e fonêmica.

É interessante observar que os subtestes fonêmicos, que foram os mais difíceis para a presente amostra, não se mostraram correlacionados com a nota escolar em nenhuma das quatro séries. Ou seja, apesar das notas terem se correlacionado mais fortemente com subtestes cada vez mais dificeis, as maiores correlações não chegaram a ser com os subtestes fonêmicos. Isso pode sugerir que tais subtestes são especialmente importantes para séries ainda mais avançadas.

A partir dessas evidências de que a importância relativa dos componentes da consciência fonológica muda no decorrer das séries sucessivas, pode-se supor que se alteram, também, as dificuldades encontradas no processo de aquisição da leitura e escrita devidas a problemas com a consciência fonológica. Assim, por exemplo, pobre desenvolvimento da consciência fonológica pode refletir dificuldades com o julgamento de rimas e aliterações na $1^{\mathrm{a}}$ série do ensino fundamental, mas dificuldades com transposição de sílabas ou de fonemas em séries mais avançadas.

Desse modo, apenas uma avaliação global da consciência fonológica caracteriza-se como insuficiente, e até mesmo inadequada, perante a complexidade dos processos envolvidos (Grégoire, 1997; Muter, Snowling \& Taylor, 1994; Perfetti e cols., 1987). Torna-se relevante e fundamental uma avaliação detalhada e pormenorizada de cada componente da consciência fonológica, pois somente em posse de dados precisos o diagnóstico poderá subsidiar uma intervenção eficaz, dirigida à natureza do problema identificado.

Finalizando, o estudo revelou que a PCFO é válida para avaliar consciência fonológica em crianças, especificamente de $1^{a}$ a $3^{a}$ série do ensino fundamental, visto que discriminou entre tais séries, apresentando um padrão de resposta esperado a partir da bibliografia da área. Além disso, os escores total e em cada subteste da prova apresentaram correlações positivas e significativas entre si e, de forma geral, com as notas escolares. Deste modo, este estudo também contribuiu para disponibilizar um instrumento que avalia a consciência fonológica, habilidade essencial à aquisição de leitura e escrita em ortografias alfabéticas como o português. Diante das limitações observadas nesta pesquisa, tais como presença de alunos repetentes, grande variabilidade de idades $\mathrm{e}$ número ainda limitado de participantes, estudos futuros deverão ser conduzidos visando a análises mais refinadas sobre o desenvolvimento dos componentes da consciência fonológica em crianças do ensino fundamental.

\section{Referências}

Alegria, J., Leybaert, J. \& Mousty, P. (1997). Aquisição da leitura e distúrbios associados: avaliação, tratamento e teoria. Em J. Grégoire \& B. Piérart (Orgs.). Avaliação dos problemas de leitura: Os novos modelos teóricos e suas implicagões diagnósticas (pp. 105124). Porto Alegre: Artes Médicas.

Baker, E. \& Bernhardt, B. (2004). From hindsight to foresight: Working around barriers to success in phonological intervention. Child Language Teaching and Therapy, 20(3), 287-318.

Bertelson, P. \& De Gelder, B. (1989). Learning about reading from illiterates. Em A. M. Galaburda (Org.). From reading to neurons (pp. 1-25). Cambridge, MA: The MIT Press.

Psico-USF, v. 12, n. 1, p. 55-64, jan./jun. 2007 
Blischak, D. M. (1994). Phonologic awareness: Implications for individuals with little or no functional speech. Augmentative and Alternative Communication, 10, 245-254.

Bowey, J. A. (1994). Phonological sensitivity in novice readers and nonreaders. Journal of Experimental Child Psychology, 58, 134-159.

Capovilla, A. G. S. \& Capovilla, F. C (1998). Prova de consciência fonológica: desenvolvimento de dez habilidades da pré-escola à segunda série. Temas sobre Desenvolvimento, 7(37), 14-20.

Capovilla, A. G. S. \& Capovilla, F. C. (2004a). Problemas de leitura e escrita: como identificar, prevenir e remediar numa abordagem fônica. São Paulo: Memnon.

Capovilla A. G. S. \& Capovilla, F. C. (2004b). Alfabetização: método fônico ( $3^{\mathrm{a}}$ ed.). São Paulo, SP: Memnon.

Capovilla, A. G. S., Capovilla, F. C. \& Silveira, F. B. (1998). O desenvolvimento da consciência fonológica, correlações com leitura e escrita e tabelas de estandardização. Ciência Cognitiva: Teoria, Pesquisa e Aplicação, 2(3), 113-160.

Cardoso-Martins, C. (1995). Sensitivity to rhymes, syllables, and phonemes in literacy acquisition in Portuguese. Reading Research Quarterly, 30(4), 808-828.

Carrol, J. M., Snowling, M. J., Stevenson, J. \& Hulme, C. (2003). The development of phonological awareness in preschool children. Developmental Psychology, 39(5), 913-923.

Demont, E. (1997). Consciência fonológica, consciência sintática: que papel (ou papéis) desempenha na aprendizagem eficaz da leitura? Em J. Grégoire \& B. Piérart (Orgs.). Avaliação dos problemas de leitura: os novos modelos diagnósticos e suas implicações diagnósticas (pp. 189202). Porto Alegre: Artes Médicas.

Elbro, C., Rasmussen, I. \& Spelling, B. (1996). Teaching reading to disabled readers with language disorders: A controlled evaluation of synthetic speech feedback. Scandinavian Journal of Psychology, 37, 140-155.

Ferracini, F. (2005). Evidências de validade de instrumentos para avaliação de linguagem oral em pré-escolares. (Dissertação de Mestrado). Itatiba: Universidade São Francisco.

Foy J. G. \& Mann, V. (2001). Does strength of phonological representations predict phonological awareness in preschool children? Applied Psycholinguistics, 22(3) 301-325.

Frith, U. (1985). Beneath the surface of developmental dyslexia. Em K. Patterson, J. Marshall \& M.
Coltheart (Orgs.). Surface dyslexia: Neuropsychological and cognitive studies of phonological reading. London, UK: Erlbaum.

Gibson, L. Y., Hogben, J. H. \& Fletcher, J. (2006). Visual and auditory processing and component reading skills in developmental dyslexia. Cognitive Neuropsychology, 23(4), 621-642.

Goswami, U. (1997). Learning to read in different orthographies: phonological awareness, orthographic representations and dyslexia. Em C. Hulme \& M. Snowling (Orgs.). Dyslexia: Biology, cognition and intervention (pp. 131-152). London, UK: Whurr.

Grégoire, J. (1997). O diagnóstico dos distúrbios de aquisição de leitura. Em J. Grégoire \& B. Piérart (Orgs.). Avaliação dos problemas de leitura: os novos modelos diagnósticos e suas implicações diagnósticas (pp. 35-52). Porto Alegre: Artes Médicas.

Jenkins, R. \& Bowen, L. (1994). Facilitating development of preliterate children's phonological abilities. Topics in Language Disorders, 14(2), 26-39.

Maluf, M. R. \& Barrera S. D. (1997). Consciência fonológica e linguagem escrita em pré-escolares. Psicologia: Reflexão e Crítica, (10)1, 125-145.

Mann, V. A. \& Foy J. G. (2003). Phonological awareness, speech development and letter knowledge in preschool children. Annals of Dyslexia, 53, 149-173.

Morais, J. (1995). A arte de ler. São Paulo, SP: Editora Unesp.

Morais, J., Bertelson, P., Cary, L. \& Alegria, J. (1986). Literacy training and speech segmentation. Cognition, $24,45-64$.

Muter, V., Snowling, M. \& Taylor, S. (1994). Orthographic analogies and phonological awareness: Their role and significance in early reading development. Journal of Child Psychology and Psychiatry, 35, 293-310.

Perfetti, C. A., Beck, I., Bell, L. \& Hughes, C. (1987). Phonemic knowledge and leaning to read are reciprocal: A longitudinal study of first grade children. Merrill-Palmer Quarterly, 33, 283-319.

Roazzi, A. \& Dowker, A. (1989). Consciência fonológica, rima e aprendizagem da leitura. Psicologia: Teoria e Pesquisa, 5, 31-55.

Santos, A. A. A. (1996). A influência da consciência fonológica na aquisição da leitura e da escrita. Em F. F. Sisto, G. C. Oliveira, L. D. T. Fini, M. T. C. C. Souza \& R. P. Brenelli (Orgs). Atuação psicopedagógica $e$ aprendizagem escolar (pp. 213-241). Petrópolis: Vozes. 
Schneider, W., Roth, E. \& Ennemoser, M. (2000). Training phonological skills and letter knowledge in children at risk for dyslexia: a comparison of three kindergarten intervention programs. Journal of Educational Psychology, 92(2), 284-295.

Share, D. (1995). Phonological recoding and selfteaching: Sine qua non of reading acquisition. Cognition, 55(2), 151-218.

Simos, P. G., Breier, J. I., Fletcher, J. M., Foorman, B. R., Mouzaki, A. \& Papanicolau, A. C. (2001). Agerelated changes in regional brain activation during phonological decoding and printed word recognition. Developmental Neuropsychology, 19, 191-210.

Stanovich, K. E., Cunningham, A. E. \& Cramer, B. R. (1984). Assessing phonological awareness in kindergarten children: Issues of task comparability. Journal of Experimental Child Psychology, 38, 175-190.

Supple, M. (1986). Reading and articulation. British Journal of Audiology, 20, 209-214.

Temple, E., Deutsch, G. K., Poldrack, R. A., Miller, S. L., Tallal, P., Merzenich, M. M., \& Gabrieli, J. D. E. (2003). Neural deficits in children with dyslexia ameliorated by behavioral remediation: Evidence from functional MRI. PNAS - Proceedings of the National Academy of Sciences of the United States of America, 100(5), 2860-2865.
Thatcher, K. L. (2003). Phonological awareness in children with specific language impairment. Dissertation Abstracts International, 64(5-B), 2158.

Torgesen, J. K. \& Davis, C. (1996). Individual difference variables that predict response to training in phonological awareness. Journal of Experimental Child Psychology, 63, 1-21.

Torgesen, J. K., Wagner, R. K. \& Rashotte, C. A. (1994). Longitudinal studies of phonological processing and reading. Journal of Learning Disabilities, 27(5), 276-286.

Varanda, C. A. (2006). Desenvolvimento do vocabulário auditivo, leitura e consciências fonológica e sintática no ensino fundamental. (Dissertação de Mestrado). São Paulo: Universidade de São Paulo.

Warrick, N., Rubin, H. \& Rowe-Walsh, S. (1993). Phoneme awareness in language delayed children: comparative studies and intervention. Annals of Dyslexia, 43, 153-173.

Sobre os autores:

Recebido em junho de 2006 Reformulado em março de 2007 Aprovado em abril de 2007

\begin{abstract}
Alessandra Gotuzo Seabra Capovilla é doutora em Psicologia Experimental (USP-Fapesp), com Pós-Doutorado em Psicologia Cognitiva da Leitura (USP-Fapesp). Jovem pesquisadora (Fapesp) e pesquisadora bolsista de Produtividade $(\mathrm{CNPq})$ na área de avaliação e intervenção em neuropsicologia, em desenvolvimento infantil e em distúrbios de linguagem escrita, é professora orientadora do Programa de Pós-Graduação Stricto Sensu em Psicologia
\end{abstract} da Universidade São Francisco.

Natália Martins Dias é graduanda em Psicologia e bolsista de Iniciação Científica pelo CNPq do Laboratório de Avaliação Psicológica em Saúde Mental, Programa de Pós-Graduação Stricto Sensu em Psicologia da Universidade São Francisco.

José Maria Montiel é psicológo, mestre e doutorando, com bolsa CAPES, em Psicologia no Programa de PósGraduação Stricto Sensu em Psicologia da Universidade São Francisco. 